\title{
Investigation on the Aluminum-alloy Surface with Micro-pits Array Generating by through Double Mask Electrochemical Machining
}

\author{
Shuangqing Qian ${ }^{1}$ \\ ${ }^{1}$ College of Mechanical Engineering, \\ Nantong University, \\ Nantong, China
}

\author{
Feng $\mathrm{Ji}^{2}$ \\ ${ }^{2}$ Xinglin College, \\ Nantong University, \\ Nantong, China
}

\begin{abstract}
For the status of low precision during micro-pit machining on the aluminum surface, a double mask electrochemical process is proposed. Pitting corrosion could be eliminated with higher current density and the lateral etching could be decreased with $\mathrm{NaNO}_{3}$ solution. Using optimized machining parameters, the uniform micro-pits array was produced on the aluminum-alloy surface. The experiment results showed that mask electrochemical process can improve machining localization on the aluminum surface.
\end{abstract}

Keywords-aluminum-alloy; double mask; electrochemical machining; micro-pits array

\section{INTRODUCTION}

Currently, about $1 / 3-1 / 2$ of the world's energy is consumed in various forms of friction loss. The control of friction, reduction of wear, and improvement on the lubrication performance have become an important aspect of saving energy and raw materials [1]. Research shows that the relatively independent and evenly distributed surface texture has been proved to be an effective means of improving tribological properties of friction pair surface with its excellence in friction and wear reduction, and improving the bearing capacity [2]. Surface texturing technology refers to machining regularly arranged certain sizes of small pits or grooves on the surface of the friction pair, which is an important guarantee to promote the research of surface texture [3].

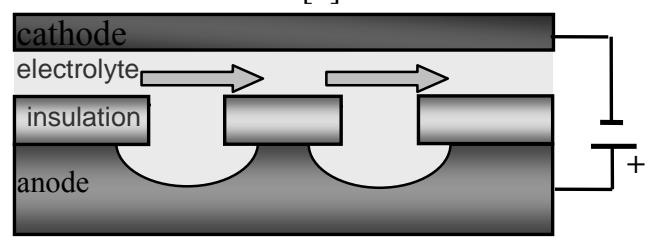

Figure 1. Electrochemical machining with the single layer mask.

Micro-pit array on the surface of friction pair is usually made up by thousands of to tens of thousands of circular or non-circular pits with the diameter ranging from $50 \mu \mathrm{m}$ to $300 \mu \mathrm{m}$, which belongs to the typical Micro/Meso processing task. In recent years, domestic and foreign researchers have proposed many kinds of effective micro pits array processing techniques on the friction pair surface, such as laser processing surface texture technology [4], abrasive jet machining technology [5], and electrochemical machining technology [6].
Compared with other processing technology, electrochemical machining, due to its remarkable features of zero loss of tool electrode, processing stress-free and deformationfree on the workpiece surface, heat affected zone, and high processing efficiency, has attracted the attention of domestic and foreign scholars [7].

Double template electrochemical machining technology is an effective method for machining surface texture of friction pairs. The double template electrochemical machining has high-accuracy surface micro pits, and meanwhile, the double template can be repeatedly used, which can greatly improve the efficiency and reduce costs. Aluminum alloy is a kind of nonferrous metal structural material which has been most widely used in industry at present, especially in aerospace, automotive, machinery manufacturing, ships and in the chemical industry. This paper will conduct a basic research on machining micro pits on the surface of aluminum alloy materials through double template electrochemical machining technology. According to the arrangement characteristics of electrodes in the machining process of double template electrochemical machining, an electrolytic machining test platform is constructed to carry out the experimental study.

\section{THE TEST PRINCIPLE}

As shown in Figure 1, in the process of traditional electrochemical machining with the single layer mask, the insulation layer is directly covered on the work piece anode with a certain amount of machining gap maintained between the cathode and work piece. High-speed electrolyte flow through the machining gap, and when the cathode and anode are powered on, the unshielded portion of the anode surface is dissolved. The machining product is carried away by the high-speed electrolyte from the machining gap, forming a micro pit morphology similar to the pierced graphic of the template on the work piece surface.

In order to reduce the distance between the anode and cathode and improve the machining efficiency, this paper adopts the electrochemical machining with the double mask for surface texturing, with the machining schematic diagram shown in Figure 2. The tool cathode has the same pierced patterns as the template covered on the workpiece anode. High-speed electrolytes flow through the cathode surface, and when the power supply is switched on, the unshielded portion on the anode surface is being dissolved, with the machining products carried away by the high- 
speed electrolyte from the machining gap, forming a double mask on the workpiece surface. micro pit morphology similar to the pierced graphic of the

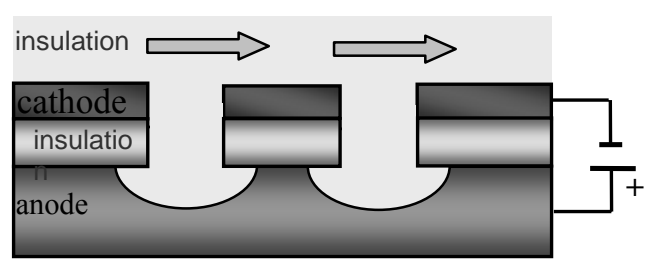

Figure 2. Electrochemical machining with the double mask

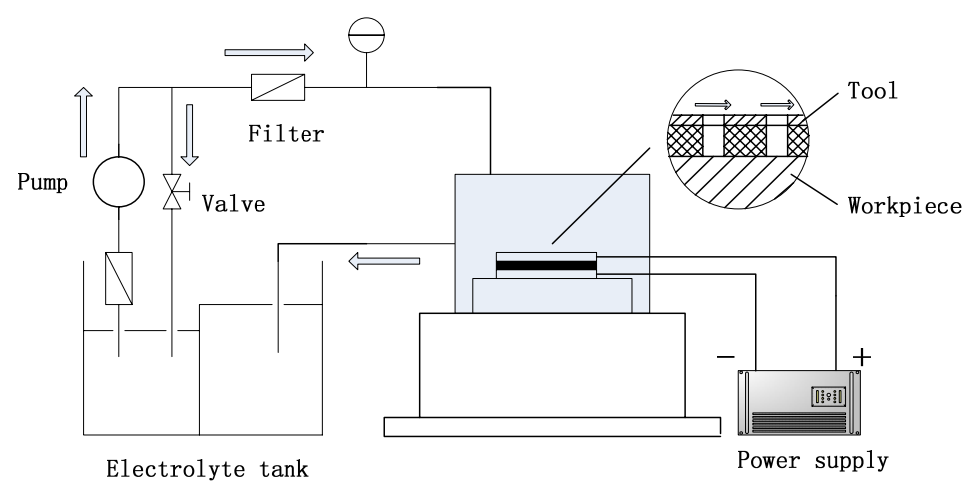

Figure 3. The Schematic of experiment system.

\section{THE ELECTROCHEMICAL MACHINING SYSTEM}

The electrochemical machining with double mask for surface texture on the aluminum alloy is carried out in the self-developed electrochemical machining cell. As shown in Figure 3, the experiment system consists of electrolytes, the electrolyte circulating system, electrochemical machining fixture system of micro pits and power supply. The working platform of machine tool is made of stainless steel material, which can prevent the electrolyte corrosion. For fixture materials, corrosion resistant organic glass material (PMMA) is selected, which can play the role of insulation and anti-corrosion. The electrolyte circulating system is composed of a pump, electrolytic tank, electrolyte filtration system, piping and valves, etc. During the machining process, the power supply comes from the GR$3015 \mathrm{~mm}$ DC power of RiYi Power Company, with the maximum output voltage of $30 \mathrm{~V}$, and the electrolyte temperature controls at $30 \pm 2{ }^{\circ} \mathrm{C}$ in the process. After the end of machining, the US three-dimensional MicroXAM3D Profiler is adopted to test the three-dimensional morphology of micro pits on the work piece surface and obtain their section size.

\section{EXPERIMENT RESULTS AND ANALYSIS}

\section{A. Effects of Current Density on the Experiment Results}

The current density is an important parameter in electrochemical machining process. This test studies the effects of current density on double mask electrochemical machining of aluminum alloy material.
In the course of electrochemical machining with double mask on the surface of aluminum alloy, the current density is set to $i=5 \mathrm{~A} / \mathrm{cm}^{2}$, as shown in Figure 4(a). The surface morphology of aluminum alloy material exhibits irregular spot corrosion, which is called "pitting" in electrochemical machining. As the metal components aluminum, silicon, magnesium and copper in the aluminum alloy material have different electrode potentials, components of phases will be dissolved in various orders in electrochemical machining process.

When the current density is taken low, phases with more negative electrode and potentials will be dissolved prior to other ones, while those with high electrode and potentials will not be dissolved, thus forming pitting and spalling on the surface of aluminum alloy.

During the experiment, when the current density is increased to $i=25 \mathrm{~A} / \mathrm{cm}^{2}$, each element in aluminum alloy materials has reached the dissolution potential, and therefore, components of all phases begin to be dissolved. Consequently, pitting phenomenon on the machined surface of the aluminum alloy material disappears, with the surface quality improved and roughness decreased. Regular micro pit morphology forms on the machined areas, as shown in Figure 4(b).

\section{B. Influence of Electrolyte Composition on Experiment Results}

Electrolyte composition is another important factor affecting the results of the electrolysis process. This experiment respectively studied the influence of neutral linear electrolyte $\mathrm{NaCl}$ solution and the nonlinear electrolyte $\mathrm{NaNO}_{3}$ solution on the micropits of the surface of 
electrochemical machined aluminum alloy with double mask.

Respectively take the $\mathrm{NaCl}$ solution and $\mathrm{NaNO}_{3}$ solution with the mass concentration of $18 \%$ as the electrolyte of electrochemical machining, and processing time is set to three seconds. The morphology of micro pits on the surface of aluminum alloy is shown in Figure 5.

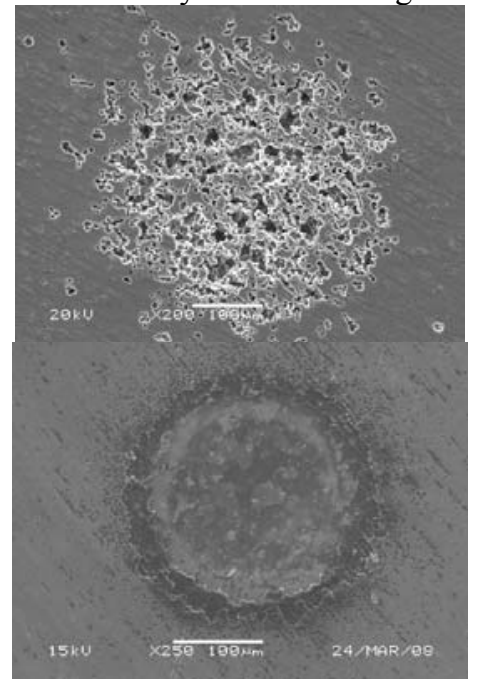

Figure 4. Surface morphology of aluminum alloy material (a) $\mathrm{i}=5 \mathrm{~A} / \mathrm{cm}^{2} ;$ (b) $\mathrm{i}=25 \mathrm{~A} / \mathrm{cm}^{2}$.
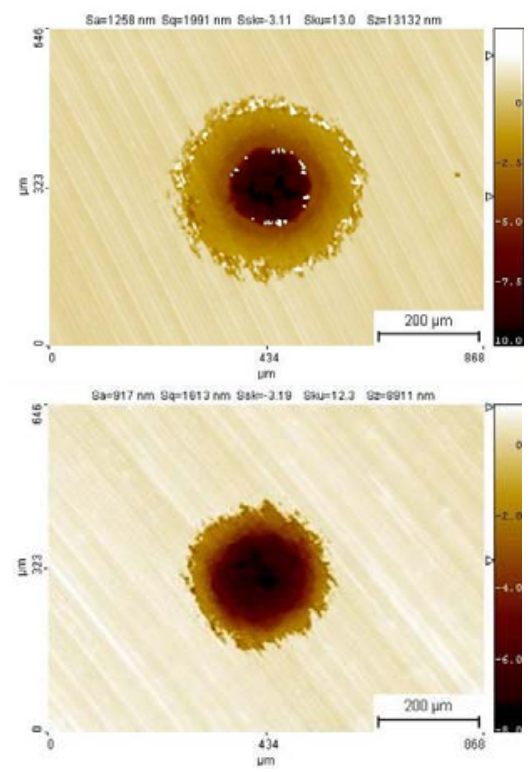

Figure 5. Surface morphology of aluminum alloy material. (a) $\mathrm{NaCl}$ solution; (b) $\mathrm{NaNO} 3$ solution.

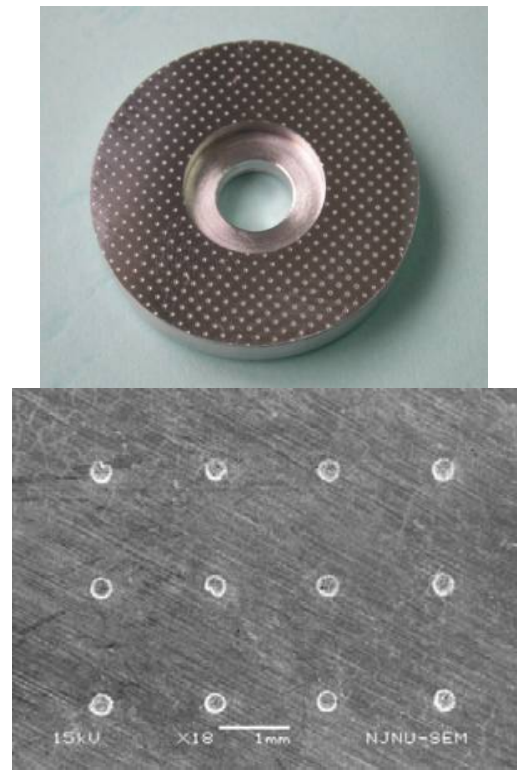

Figure 6 . The machining result on the aluminum alloy surface. (a) The profile of aluminum alloy work piece. (b) The magnified morphology of micro pits.

The micro pit side machined by using $\mathrm{NaCl}$ solution as electrolyte displays high corrosion, with an average diameter of $350 \mu \mathrm{m}$ and an average depth of $10 \mu \mathrm{m}$, as shown in Figure 5(a). The corrosion coefficient of micro pit is calculated as 0.133 . However, the micro pit side machined by using $\mathrm{NaNO}_{3}$ solution as electrolyte has small corrosion, with an average diameter of $290 \mu \mathrm{m}$ and an average depth of $8 \mu \mathrm{m}$, as shown in Figure 5(b). The corrosion coefficient of micro pits is calculated as 0.178 . Thus, the nonlinear $\mathrm{NaNO}_{3}$ electrolyte solution can effectively reduce the lateral corrosion for the electrochemical machining of micro pits to improve the locality of the template electrochemical machining.

\section{Machining Optimization}

In view of the effects of current density and electrolyte composition on the electrochemical machining results, it is necessary to optimize the electrochemical machining parameters of electrochemical machining with double mask of micro pits on aluminum alloy surface. The $\mathrm{NaNO}_{3}$ solution with the concentration of $18 \%$ is taken as electrolyte in electrochemical machining, and the current density is set to $i=25 \mathrm{~A} / \mathrm{cm}^{2}$ during the process. Regular micro-pit array morphology appears on the aluminum alloy surface after the end of machining, as shown in Figure 6. Figure 6(a) shows the profile of aluminum alloy work piece, while Figure 6(b) displays the magnified morphology of micro pits on the workpiece surface.

\section{CONCLUSION}

This paper, based on the characteristics of aluminum alloy material, has studied the effects of current density and electrolyte compositions on the morphology of micropit array on aluminum alloy surface in the electrochemical machining process with double mask. The experiment 
results show that low current density will cause pitting phenomenon on the work piece surface, while increasing the current density can eliminate that. Meanwhile, using the sodium nitrate solution as the electrolyte can effectively reduce the lateral corrosion of micro-pit array.

\section{ACKNOWLEDGMENT}

The research work was supported by the National Natural Science Foundation of China (Grant No. 51305212 ), the Natural Science Foundation of the Jiangsu Higher Education Institutions of China (Grant No. 13KJB460014) and Program of Application Research of Nantong (Grant No. BK2012053).

\section{REFERENCES}

[1] M. Wakuda, Y. Yamauchi, S. Kanzaki, Y. Yasuda, Effect of surface texturing on friction reduction between ceramic and steel materials under lubricated sliding contact. Wear, 254, pp. 356-363, 2003.

[2] A. Blatter, M. Maillat, S.M. Pimenov, G.A. Shafeev, A.V. Simakin, E.N. Loubnin, Lubricated sliding performance of laser-patterned sapphire. Wear, 232, pp. 226-230, 1999.

[3] G. Ryk, Y. Kligerman, I. Etsion, Experimental investigation of laser surface texturing for reciprocating automotive components. Tribol Trans., 45, pp. 444-449, 2002.

[4] X. Wang, K. Kato, K. Adachi, K. Aizawa, The effect of laser texturing of Sic surface on the critical load for the transition of water lubrication mode from hydrodynamic to mixed. Tribol. Int., 34, pp. 703-711, 2001.

[5] M. Wakuda, Y. Yamauchi, S. Kanzaki, Material response to particle impact during abrasive jet machining of alumina ceramics. J. Mater. Process. Technol., 132, pp. 177-183, 2003.

[6] B. Bhattacharyya, B. Doloi, P.S. Sridhar, Electrochemical micromachining: new possibilities for micro-manufacturing. J. Mater. Process. Technol., 113, pp. 301-305, 2001.

[7] M. Malapati, B. Bhattacharyya, Investigation into electrochemical micromachining process during micro-channel generation. Mater. Manuf. Process., 26(8), pp. 1019-1027, 2011. 